\title{
Photochromic dynamics of organic-inorganic hybrids supported on transparent and flexible recycled PET
}

\author{
R.P. Cruz ${ }^{\text {a }}$, M. Nalin ${ }^{\text {b }, ~ S . J . L . ~ R i b e i r o ~}{ }^{\mathrm{b}}$, C. Molina ${ }^{\mathrm{a},{ }^{*}}$ \\ a Institute of Environmental, Chemical and Pharmaceutical Sciences - Federal University of São Paulo, Diadema, SP, Brazil \\ ${ }^{\mathrm{b}}$ Chemistry Institute, São Paulo State University - UNESP, Araraquara, SP, Brazil
}

\section{A R T I C L E I N F O}

\section{Article history:}

Received 11 October 2016

Received in revised form

9 February 2017

Accepted 10 February 2017

Available online 20 February 2017

\section{Keywords:}

Photochromic

Sol-gel

Hybrids

Transparent recycled PET

Polyoxometalates

\begin{abstract}
A B S T R A C T
Organic-inorganic hybrids (OIH) synthesized by sol gel process containing phosphotungstic acid (PWA) entrapped have been attracted much attention for ultraviolet sensitive materials. However, the limitations for practical photochromic application of these materials are the poor interaction with flexible polymer substrates such as Poly(ethyleneterephthalate) (PET) and also photo response under ultraviolet radiation. This paper describes the use of the d-ureasil HOI, based on siliceous network grafted through linkages to both ends of polymer chain containing 2.5 poly(oxyethylene) units with PWA entrapped prepared as films on recycled PET. Films were characterized by IR-ATR, XRD, TG/DTG, UV-Vis and Contact angle. XRD patterns showed that both pristine hybrid matrix and those containing PWA are amorphous. IR showed that PWA structure is preserved in the matrix and interactions between them occur by intermolecular forces. Films are thermally stable up to $325^{\circ} \mathrm{C}$ and contact angle of $25.1^{\circ}$ showed a good wettability between substrate and hybrid matrix. Furthermore, films showed fast photochromic response after $1 \mathrm{~min}$ of ultraviolet exposure time. The bleaching process revealed that the relaxation process is dependent of the temperature and the activation energy of $47.2 \mathrm{~kJ} \mathrm{~mol}^{-1}$ was determined. The properties of these films make them potential candidates for applications in flexible photochromic materials.
\end{abstract}

() 2017 Elsevier B.V. All rights reserved.

\section{Introduction}

Organic Inorganic Hybrid (OIH) materials containing polyoxometalates (POMs) entrapped have attracted enormous attentions which make them suitable for photochromic applications [1-9]. Phosphotungstic acid (PWA), a Keggin structure, represented by $\mathrm{H}_{3} \mathrm{PW}_{12} \mathrm{O}_{40}$ formula is one of the most important POM used due to its solubility in many solvents, defined size and structure and mainly due to the photoreduction of its $\mathrm{W}^{6+}$ species under ultraviolet irradiation which promotes change of color [10]. d-ureasil is an interesting class II hybrid material, synthesized by sol gel process, composed by variable polyethylene oxide units covalently bonded to silicon atoms at both sides through urea groups [11]. The molecular weight of the polymer chain can be tuned which affects the photochromic behavior [12]. Usually, photochromic materials are employed in films deposited on rigid substrate like glass. However, for flexible polymeric substrates

\footnotetext{
* Corresponding author.

E-mail address: cmolina@unifesp.br (C. Molina).
}

more investigation becomes necessary. Poly(ethylene terephthalate) (PET) has been widely applied in many different fields such as food packages, drink bottles, displays, etc. It has advantages such as flexibility, high transparency in the visible range, dimensional stability, solvent resistance and thermal stability [13]. Tricot et al. have obtained photochromic Ag: $\mathrm{TiO}_{2}$ thin films on PET substrate in two steps by sol gel process and evaporation induced by self-assembly method [14]. Filpo et al. have obtained photoelectrochromic (PET)-TiO $2-\mathrm{PO}_{4}-$ Methylene blue by the deposition of $\mathrm{TiO}_{2}$ nanoparticles on PET conductive substrate [15]. Bessière et al. have deposited electrochromic tungsten oxide films on PET covered with ITO [16]. A common drawback to use flexible PET for optical application is the price and commercial availability. According to the principles of the green chemistry, challenges that should be taken into account are recycling and designing of materials, considering a sustainable approach [17]. Recycled PET (RPET) has been applied, for example, in nanocomposites to improve mechanical, thermal and optical properties [18]. Moreover, RPET in sheets dimension (thickness in microns) transparent in a visible range can be considered as a cheaper and alternative 
substrate [19]. In this investigation, to our best knowledge, it is the first study done by using OIH based on d-ureasil deposited on transparent recycled sheet PET substrate which has potential application for photochromic flexible devices.

\section{Experimental}

\subsection{Chemicals and materials}

All chemicals were used as received. They were purchased from Huntsman (Jeffamine-D230 ${ }^{\circledR}$ ), Aldrich (3isocyanatepropyltriethoxysilane, ICPTES) and phosphotungstic acid (PWA). Recycled PET (RPET) sheets with a thickness of $250 \mu \mathrm{m}$ were supplied by $\mathrm{KGM}^{\circledR}$.

\subsection{Synthesis of the precursor d-UPTES230}

The precursor d-UPTES230 (termed d-UreaPropylTriethoxySilane, d-UPTES), where $U$ represents urea groups and $230 \mathrm{~g} \mathrm{~mol}^{-1}$ the average molecular weight of the organic chain, was synthesized grafting the polymer chains to a siliceous network by means of urea linkages. The cross-links between the organic and the inorganic parts were formed by reacting the $\mathrm{NH}_{2}$ groups of a diamine commercially named as Jeffamine-D230 ${ }^{\circledR}$, where 230 containing approximately $2.5 \mathrm{CH}_{3} \mathrm{CHCH}_{2} \mathrm{O}$ units with the $-\mathrm{N}=\mathrm{C}=\mathrm{O}$ group of 3isocyanatepropyltriethoxysilane, ICPTES in a molar ratio ICPTES: Jeffamine 2:1 in tetrahydrofuran, THF, under reflux and magnetic stirring at $80{ }^{\circ} \mathrm{C}$ for $24 \mathrm{~h}$. Precursor was isolated after evaporating the solvent [11].

\subsection{Synthesis of the hybrids $U(230)$ and $U(230) P W A$}

d-UPTES230 precursor was diluted in methanol in w:v ratio (dUPTES230: methanol (1:6)), stirred for $15 \mathrm{~min}$ and then deionised water was added in a molar ratio (d-UPTES230: $\mathrm{H}_{2} \mathrm{O}(1: 3)$ ) and the final sol was stirred for more $2 \mathrm{~h}$. For the photochromic hybrids, the same procedure described above was used, and PWA diluted in methanol was added in a molar ratio $(n=50)$ where $n$ means the molar ratio $\left[\mathrm{CH}_{3} \mathrm{CHCH}_{2} \mathrm{O}\right] /$ PWA.

\subsection{Films on flexible recycled PET}

Recycled PET (RPET) sheets with $250 \mu \mathrm{m}$ of thickness as substrates were previously cleaned with isopropanol at $60{ }^{\circ} \mathrm{C}$ for $15 \mathrm{~min}$, rinsed with deionised water and dried in nitrogen flow. Films were obtained by spin coating technique using rotation of $1000 \mathrm{rpm}$ during $20 \mathrm{~s}$ for both films with PWA RPETU(230)PWA and without RPETU(230).

IR spectra were collected at room temperature using an IR Prestige 12 Shimadzu spectrometer over the range of 2000$600 \mathrm{~cm}^{-1}$ in ATR (Attenuated Total Reflectance) mode by averaging 200 scans to the films and using $\mathrm{KBr}$ pellets to PWA.

XRD measurements were carried out using a Rigaku (Ultima+) diffractometer with $\mathrm{CuK} \alpha(1.54 \AA)$ over the $2 \theta$ range of $5-70^{\circ}$ and resolution of $0.05^{\circ}$, operating at $20 \mathrm{~mA}, \mathrm{~V}=40 \mathrm{kV}$.

Thermal analysis was performed by using a DTG-60H Shimadzu under nitrogen flux of $50 \mathrm{~mL} \mathrm{~min}{ }^{-1}$ and heating rate of $10^{\circ} \mathrm{C} \cdot \mathrm{min}^{-1}$ from 25 to $800{ }^{\circ} \mathrm{C}$.

Absorption spectra were obtained using a UV-Vis Varian 5000 Cary NIR spectrophotometer and the spectra were recorded from 200 to $2000 \mathrm{~nm}$. Kinetic measurements were performed in-situ by using an oven coupled to the spectrophotometer.

UV mercury lamp was used to irradiate films for photocoloration and kinetic measurements. All samples were maintained at the same distance $(15 \mathrm{~cm})$ to the lamp in a constant irradiance of the
$9.55 \mathrm{~mW} \mathrm{~cm}^{-2}$ for $20 \mathrm{~min}$.

Contact Angle and surface tension measurements were carried out by using a System OCA 15 plus apparatus on sessile and pendant drop configurations.

\section{Results and discussion}

Fig. 1(a-d) shows IR spectra of the recycled RPET substrate, PWA, RPETU(230) and RPETU(230)PWA films, respectively. In the case of the RPET substrate (Fig. 1a), bands at $721 \mathrm{~cm}^{-1}$ are attributed to $\nu(\mathrm{C}-\mathrm{H})$ of the aromatic ring; at $1089 \mathrm{~cm}^{-1}$ to ass $v\left(\mathrm{O}-\mathrm{CH}_{2}-\mathrm{CH}_{2}\right)$; at $1236 \mathrm{~cm}^{-1}$ to ass $v(\mathrm{C}-\mathrm{C})$ and at $1710 \mathrm{~cm}^{-1}$ to $\nu(\mathrm{C}=\mathrm{O})[20,21]$. The main band of the PWA (Fig. 1b) at $1080 \mathrm{~cm}^{-1}$ is assigned to $\nu\left(\mathrm{P}-\mathrm{O}_{\mathrm{a}}\right)$; at $987 \mathrm{~cm}^{-1}$ to $\nu\left(\mathrm{W}-\mathrm{O}_{\mathrm{d}}\right)$; at $894 \mathrm{~cm}^{-1}$ to $\nu\left(\mathrm{W}-\mathrm{O}_{\mathrm{b}}-\mathrm{W}\right)$ and at $802 \mathrm{~cm}^{-1}$ to $\nu\left(\mathrm{W}-\mathrm{O}_{\mathrm{c}}-\mathrm{W}\right)[1-3,10]$. The film $\operatorname{RPETU}(230)$ hybrid matrix (Fig. 1c), so-called d-ureasil which is based on polyether chain grafted to the silica networks by means of urea groups, present the main bands attributed to amide I and II regions. According to Bermudez et al. amide I broad band at $1642 \mathrm{~cm}^{-1}$ is attributed to a complex vibration mode of $\mathrm{N}-\mathrm{H}$ and $\mathrm{C}-\mathrm{N}$ stretching, $v \mathrm{C}-\mathrm{C},{ }_{\delta} \mathrm{C}-\mathrm{C}-\mathrm{N}$ and $v C=O$ which is sensitive to the hydrogen bonding inter polymer chain. For the amide II region, the band at $1565 \mathrm{~cm}^{-1}$ involves contribution of $v \mathrm{C}-\mathrm{N}, \mathrm{N}-\mathrm{H}$ in plane bending and $\nu \mathrm{C}-\mathrm{C}$. Moreover, an intense and broad band found at $1110 \mathrm{~cm}^{-1}$ is attributed to $v \mathrm{C}-\mathrm{O}$ from the polyether chain and $\nu(\mathrm{Si}-\mathrm{O})$ from inorganic network [11]. Besides, the spectrum of the RPETU(230) pristine film without PWA, deposited on RPET, shows RPET substrate bands as reported in Fig. 1b. Amide I, II and C-O of polyether chain of the d-ureasil hybrid $\mathrm{U}(230)$ are sensitive to the interaction with the RPET substrate through hydrogen bonding by $\mathrm{O}-\mathrm{CH}_{2}-\mathrm{CH}_{2}$ and $\mathrm{C}=\mathrm{O}$ groups of the recycled PET structure. Bands at $1634 \mathrm{~cm}^{-1}$ assigned to amide I

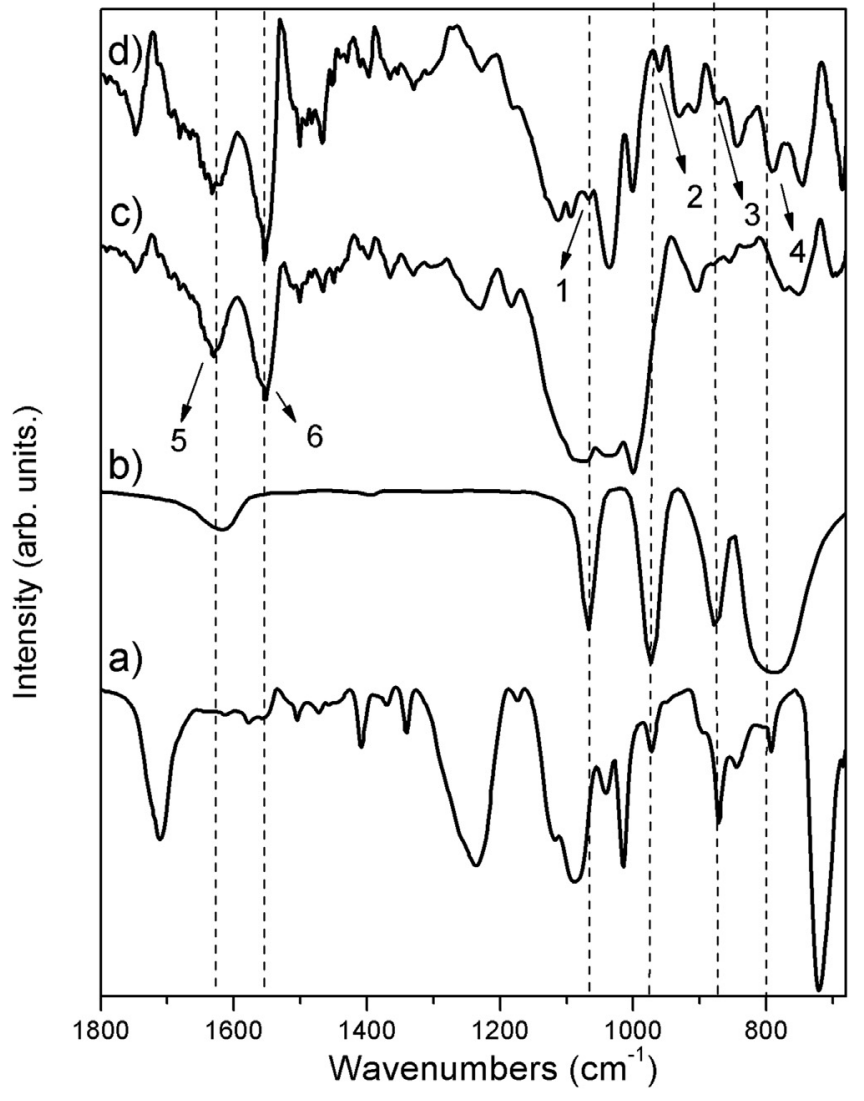

Fig. 1. IR spectra of RPET (a); PWA (b); RPETU(230) (c); and RPETU(230)PWA (d). 


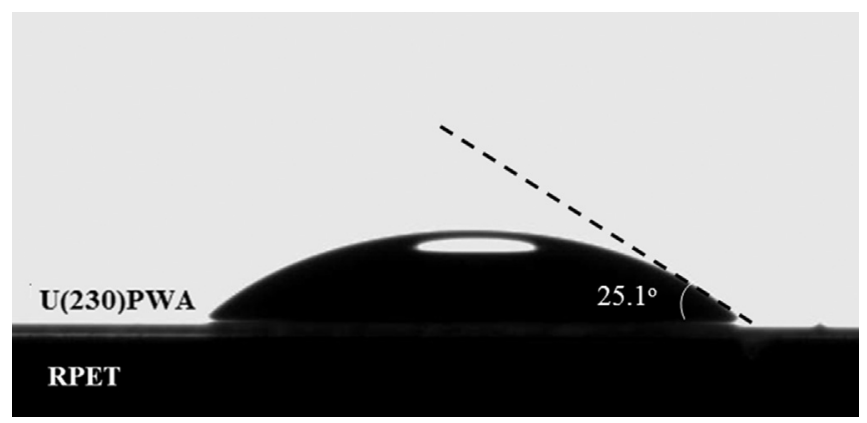

Fig. 2. Contact angle view of $25.1^{\circ}$ of a sessile drop between U(230)PWA sol and RPET.

(Fig. 1c (5), at $1558 \mathrm{~cm}^{-1}$ (Fig. 1c (6) assigned to amide II region appear shifted due to interactions between PET and hybrid film. Slight shifting of approximately 8 and $7 \mathrm{~cm}^{-1}$ observed in the spectra show interactions between $\mathrm{U}(230)$ and RPET, promoting a better wettability between them as confirmed by contact angle measurement presented below.

In the photochromic film RPETU(230)PWA in Fig 1d bands of the $\mathrm{U}(230)$ and RPET can be observed. For the fact that the bands (1), (2), (3) and (4) are attributed to PWA structure, confirms that it is preserved in the hybrid matrix. Furthermore, the slight shifting of the bands inferred for $\nu\left(\mathrm{W}-\mathrm{O}_{\mathrm{d}}\right)(2), \nu\left(\mathrm{W}-\mathrm{O}_{\mathrm{b}}-\mathrm{W}\right)(3)$ and $\nu\left(\mathrm{W}-\mathrm{O}_{\mathrm{c}}-\mathrm{W}\right)$ (4) suggest that intermolecular forces and electrostatic interactions between PWA and hybrid matrix occur $[2,22]$.

Surface tension of the U(230)PWA sol was determined by using pendent drop configuration presenting value of $24.9 \mathrm{mN} \mathrm{m}^{-1}$.

Fig. 2 shows the contact angle view of a drop of the U(230)PWA sol on flexible recycled PET substrate. This value of CA of $25.1^{\circ}$

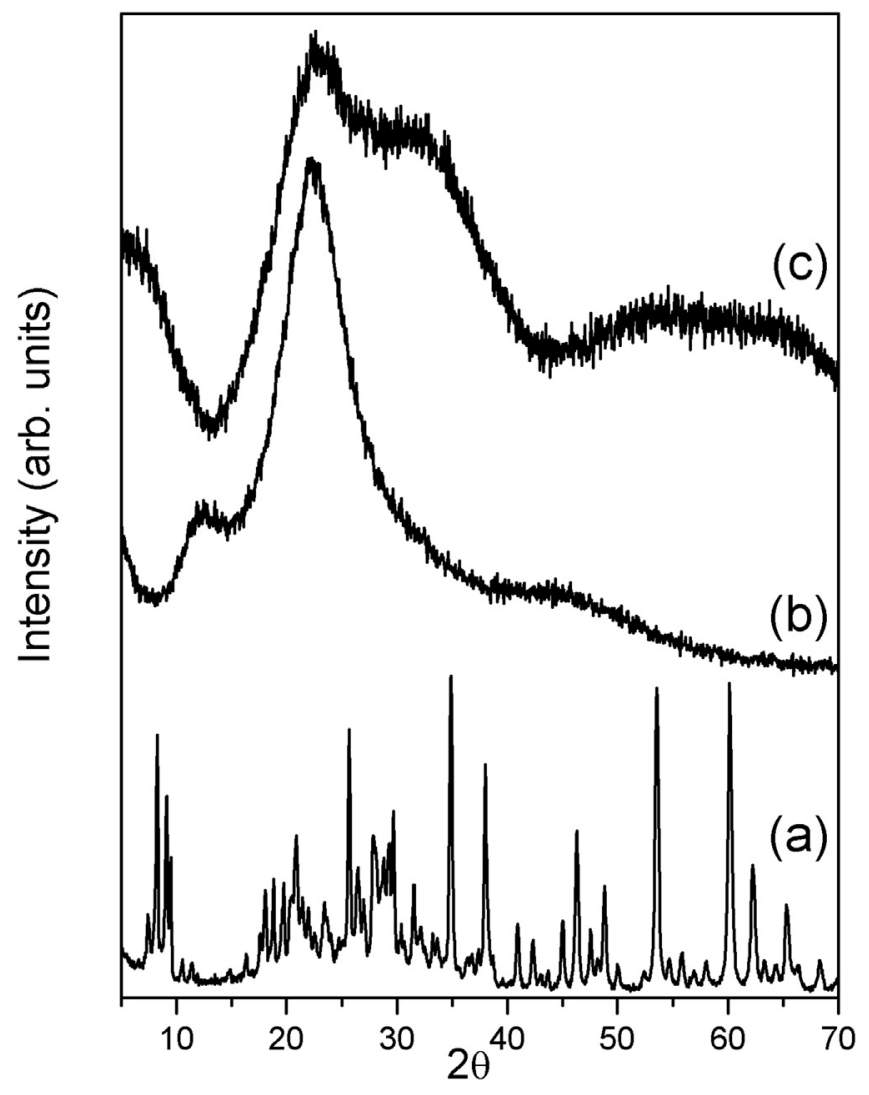

Fig. 3. XRD patterns of PWA (a), U(230) (b) and U(230)PWA (c). reveals good wettability between sol and RPET, due to intermolecular forces such as hydrogen bonding of N-H and C-O (urea and ether groups) from d-ureasil hybrid and $\mathrm{C}=\mathrm{O}$ and $\mathrm{O}-\mathrm{CH}_{2} \mathrm{CH}_{2}$ from RPET substrate. These results indicate that hybrid sol has an adequate interaction with RPET substrate providing good spreading of the sol on the substrate and, thus improving adherence and quality of the photochromic film.

Fig. 3(a-c) shows the X ray diffraction (XRD) patterns of PWA and for both hybrids $\mathrm{U}(230)$ and $\mathrm{U}(230)$ PWA. The diffraction peaks observed in Fig. 3a confirm the crystalline structure of the PWA $[2,23]$. A broad peak centered approximately at $21^{\circ}(2 \theta)$ in Fig. $3 \mathrm{~b}$ is attributed to an amorphous state of the silicon domains in d-ureasil hybrid host. Coherent length $(L)$ over which the silicon domains survive can be estimated using Scherrer equation, FWHM = $(0.94 \lambda) /(\operatorname{Lcos} \theta)$ where FWHM is full width at half maximum (in radians) of the peak and $L$ the coherent length over which the silicon domains survive. The calculated $(L)$ is approximately $15 \AA$. This value is similar to those reported to $\mathrm{U}(600), \mathrm{U}(900)$ and $\mathrm{U}(2000)$ hybrids [24]. The presence of PWA clearly affects the structure of the hybrid matrix (Fig. 3c). For the U(230)PWA, a second broad peak centered at approximately $31^{\circ}$ is attributed to the influence of the PWA in the polymer chains of the hybrid matrix.

Fig. 4 shows the TG (A) and DTG curves (B) of the RPET, U(230) and U(230)PWA. RPET substrate presents thermal stability up to approximately, $380{ }^{\circ} \mathrm{C}$ for the extrapolated onset temperature and $441{ }^{\circ} \mathrm{C}$ for the maximum temperature of degradation. These range of temperature is high enough for flexible substrate to be applied in photochromic devices. $\mathrm{U}(230)$ hybrid and $\mathrm{U}(230)$ PWA present these two temperatures at $354,386^{\circ} \mathrm{C}$ and $320,351^{\circ} \mathrm{C}$, respectively.
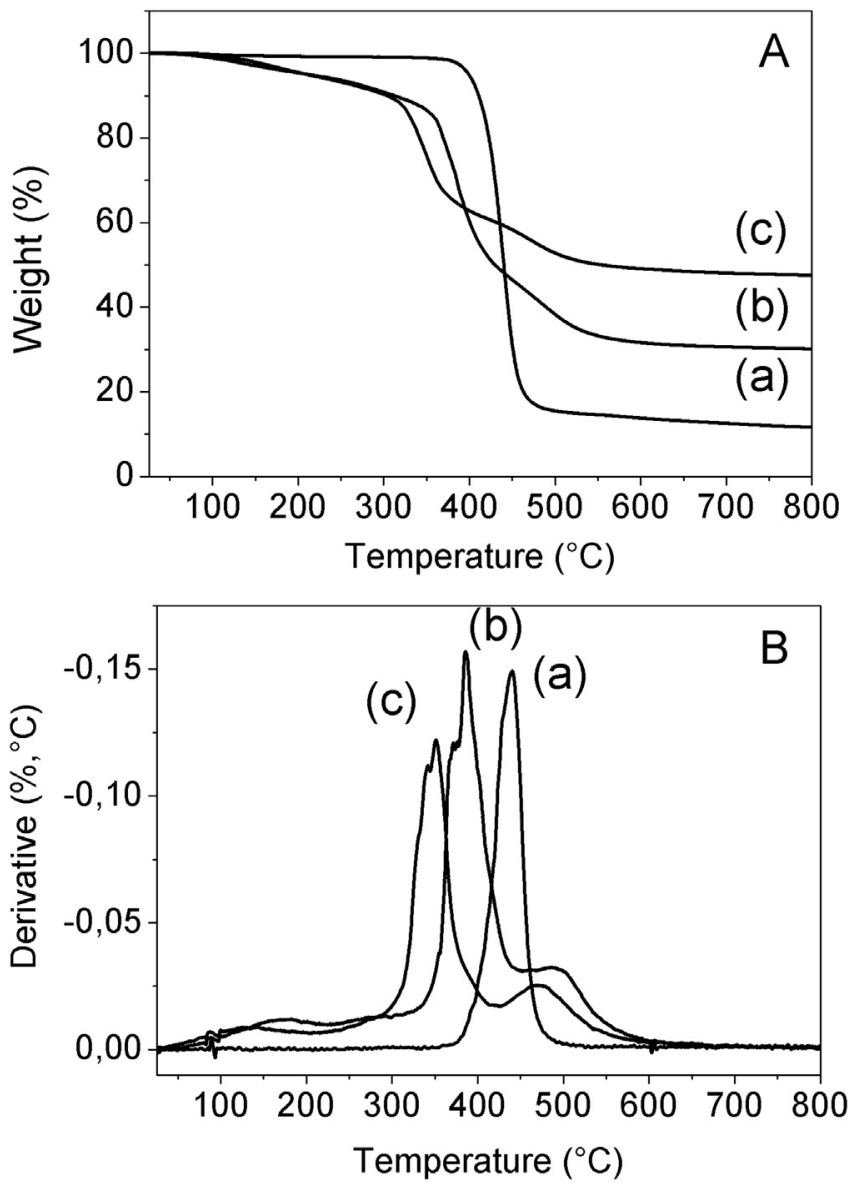

Fig. 4. TGA (A) and DTG (B) curves of RPET (a); U(230) (b) and U(230)PWA (c). 


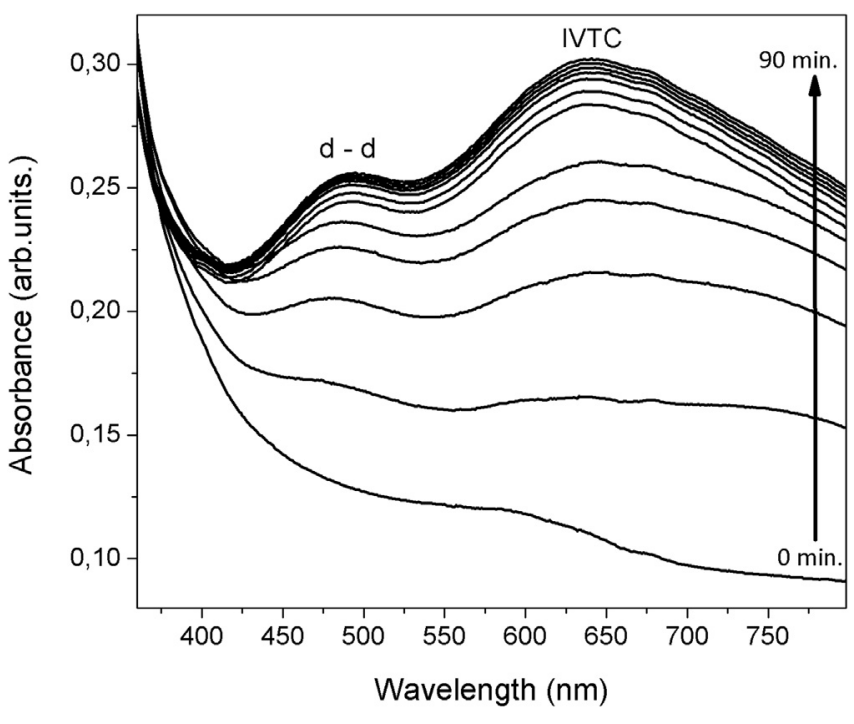

Fig. 5. UV-Vis spectra of RPETU(230)PWA film during coloring process.

Both temperatures decrease when PWA is included due to its interaction with the hybrid matrix, suggesting that polyanions affect directly the structures of internal hydrogen bonding in the polymer chain.

Fig. 5 demonstrates the photochromic behavior of the RPETU(230)PWA film followed by UV-Vis spectroscopy. Before UV exposure, no significant absorption band was observed in the range of $400-800 \mathrm{~nm}$. After UV irradiation, the color of the film, changing from transparent colorless to blue, due to reduction of the Tungsten specimens $\left(\mathrm{W}^{6+} \rightarrow \mathrm{W}^{5+}\right)[25,26]$. Two main broad bands appear, approximately, at 495 and $641 \mathrm{~nm}$ attributed to d-d and intervalence charge transfer (IVCT) transitions, respectively. We observed that the film is sensitive after $1 \mathrm{~min}$ of UV exposure time and the (IVCT) band was monitored until reaching the constant maximum blue color which occurs, approximately after 90 min.

Fig. 6 shows the bleaching process studied by UV-Vis. The films were introduced into an oven coupled to the spectrophotometer and heated at 3 different temperatures $\left(50,60\right.$ and $\left.70{ }^{\circ} \mathrm{C}\right)$ in order to study the bleaching process. Using such apparatus configuration, it was possible to collect the spectra in-situ and make possible the study of the kinetics of bleaching.

Fig. 7 show the behavior of the bleaching process monitored in the IVCT band at about $641 \mathrm{~nm}$ by means of a first order decay

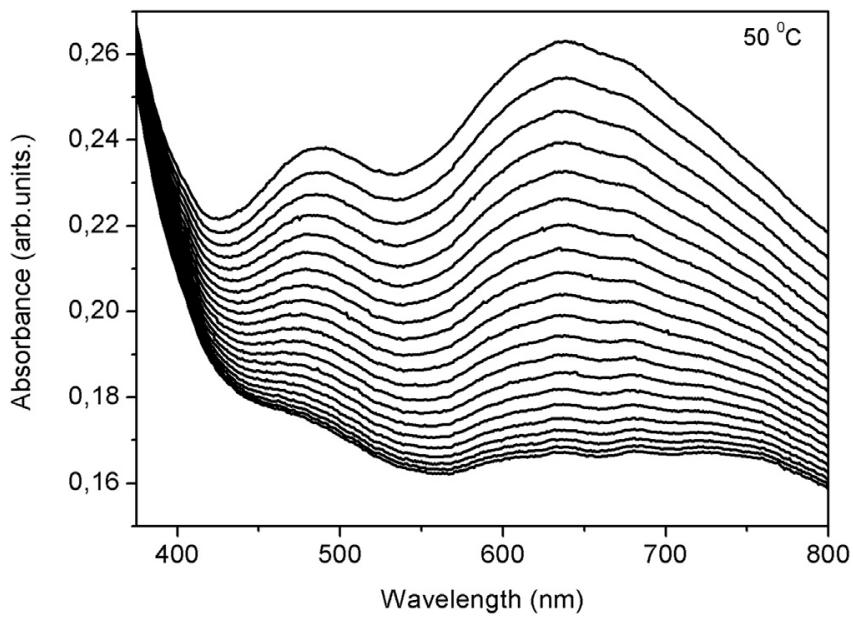

Fig. 6. UV-Vis spectra of RPETU(230)PWA films during bleaching process at $50{ }^{\circ} \mathrm{C}$
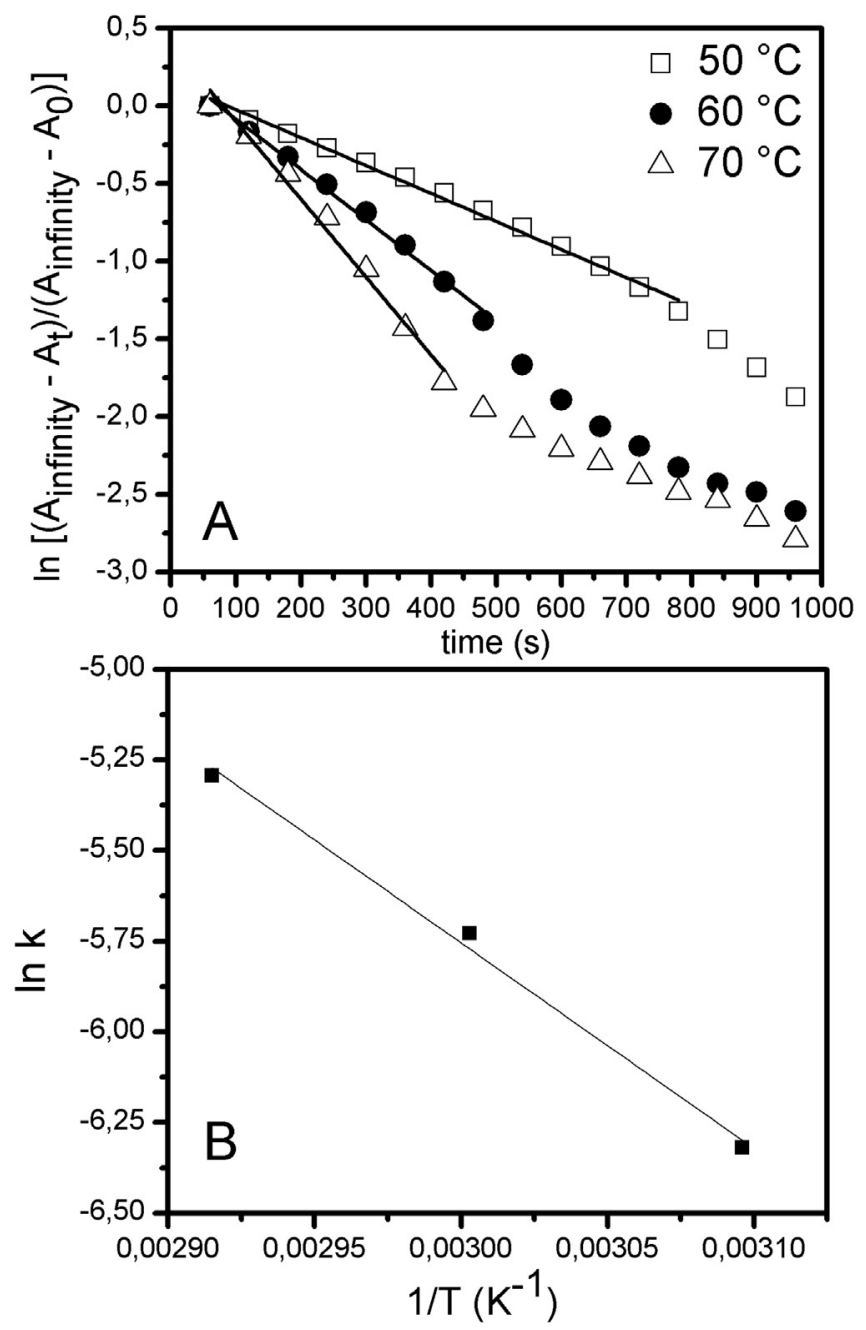

Fig. 7. $\ln \left[\left(A_{\text {infinity }}-A_{t}\right) /\left(A_{\text {infinity }}-A_{0}\right)\right]$ versus time (s) plot to 50,60 and $70{ }^{\circ} \mathrm{C}(\mathrm{A})$ and lnk versus $1 / \mathrm{T}\left(\mathrm{K}^{-1}\right)$ plot $(\mathrm{B})$ to the $\operatorname{RPETU}(230) \mathrm{PWA}$ films.

kinetics of the absorbance $A$ for three temperatures at 50,60 and $70{ }^{\circ} \mathrm{C}$ as a function of the time. The equation, $\ln \left[\left(A_{\text {Infinity }}-A_{t}\right) /\left(A_{\text {Infinity }}\right.\right.$ - $\left.A_{0}\right)$ ] versus time (s) was applied to obtain $k$ values, where $A_{t}$ is the absorption at time $\mathrm{t}, A_{0}$ at initial time, and $A_{\text {Infinity }}$ at infinity time. The activation energy, $E_{a}$, was determined applying Arrhenius plot by using equation $\ln k=\ln [A]-E_{a} / R T$. The $E_{a}$ presented value of the $47.2 \mathrm{~kJ} \mathrm{~mol}^{-1}$.

Bleaching process is related to oxidation effect over the $\mathrm{W}^{5+}$ reduced species due to diffusion of oxygen through the hybrid matrix and also by the interaction between PWA and matrix. The influence of the temperature is clearly observed as a function of the temperature. Zhong et al. have shown this behaviour in epoxy resin. They have observed that the diffusion of the oxygen through the matrix is dependent to the free spaces. A presence of the polyoxyethylene (PEO) groups affects the free volume in the polymer matrix increasing the diffusion of oxygen and consequently improving the bleaching process as a function of the PEO content. They have obtained $\mathrm{E}_{\mathrm{a}}$ for epoxy resin for three different concentrations of POM [27]. In our material, a similar behaviour was observed, once the repetition of the polymer chain in d-ureasil hybrids is polyoxypropylene (PPO). In d-ureasil hybrid network, socalled class II, the PPO or PEO units can be controlled with different polymer chain length and consequently the bleaching process can be monitored as observed in our previous work [12]. 


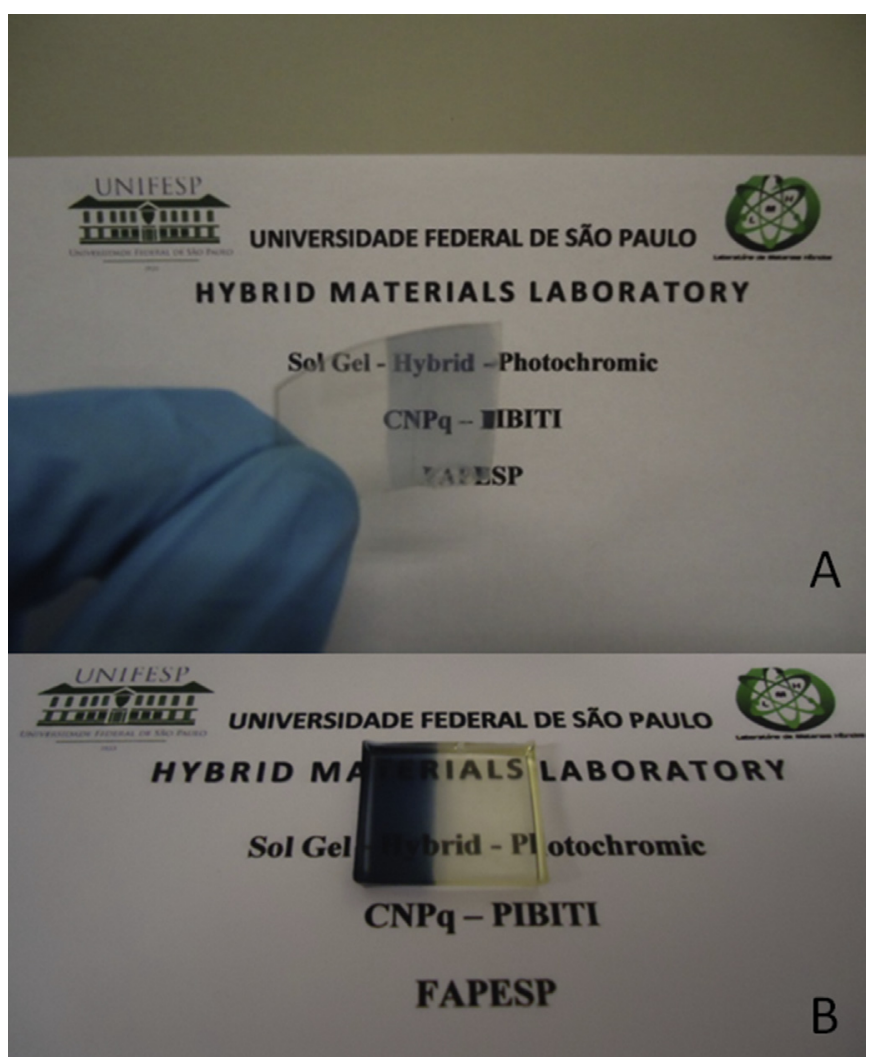

Fig. 8. Photochromic film of RPETU(230)PWA (A) and bulk U(230)PWA (B). Right side exposured to UV irradiation in film (A) and left side in bulk (B).

Fig. 8 shows the photochromic film of the RPETU(230)PWA and $\mathrm{U}(230) P W A$ in film and bulk, respectively. The thickness and transmittance (\% T) at $640 \mathrm{~nm}$ for the bulk and film are approximately $2.8 \mathrm{~mm}$ (98.8\%) and $30 \mu \mathrm{m}$ (77\%), respectively.

\section{Conclusions}

Photochromic films based on d-ureasil OIH material were obtained by sol gel process on flexible transparent recycled PET. Phosphotungstic acid was well entrapped in the hybrid matrix. The new materials presented amorphous structures and thermal stability at about $320-351{ }^{\circ} \mathrm{C}$. The value of contact angle between hybrid matrix and recycled PET substrate revealed a good wettability between interfaces showing an appropriate interaction. Flexible films presented fast photochromic response changing its color to blue after $1 \mathrm{~min}$ of ultraviolet radiation and the bleaching process is dependent of the temperature. Increasing the temperature, the bleaching time decreases. The results confirm that dureasil hybrids are good candidates for photochromic flexible devices.

\section{Acknowledgements}

The authors acknowledge the financial support from Brazilian agencies: CAPES and grants 2012/02708-8, 2013/07793-6 São Paulo Research Foundation.

\section{References}

[1] T.R. Zhang, W. Feng, R. Lu, X.T. Zhang, M. Jin, T.J. Li, Y.Y. Zhao, J.N. Yao, Thin Solid Films 402 (2002) 237-241.

[2] T.R. Zhang, W. Feng, R. Lu, C.Y. Bao, T.J. Li, Y.Y. Zhao, J.N. Yao, Mater. Chem. Phys. 78 (2002) 380-384.

[3] W. Feng, T.R. Zhang, Y. Liu, R. Lu, Y.Y. Zhao, T.J. Li, J.N. Yao, J. Solid State Chem. 169 (2002) 1-5.

[4] J. Chen, Y. Liu, D. Xiong, W. Feng, W. Cai, Thin Solids Films 516 (2008) 2864-2868.

[5] W. Feng, T.R. Zhang, Y. Liu, R. Lu, Y.Y. Zhao, J.N. Yao, J. Mater. Sci. 38 (2003) 1045-1048.

[6] Y. Mo, R.O. Dillon, P.G. Snyder, T.E. Tiwald, Thin Solids Films 355-356 (1999) $1-5$.

[7] X. Peng, Y. Zhang, W. Feng, L. Ai, J. Chen, F. Zhang, J. Mol. Struct. 1041 (2013) $139-143$.

[8] L. Ai, W. Feng, J. Chen, Y. Liu, W. Cai, Mater. Chem. Phys. 109 (2008) 131-136.

[9] E.P.F. Neto, S. Ullah, F.L.S. Carvalho, A.L. Souza, M.O Jr., J.F. Schneider Y.P. Mascarenhas, A.M. J Jr., U.P.R. Filho, Mater. Chem. Phys. 153 (2015) $410-421$.

[10] J. Yang, M.J. Janik, D. Ma, A. Zheng, M. Zhang, M. Neurock, R.J. Davis, C. Ye, F. Deng, J. Am. Chem. Soc. 127 (2005) 18274-18280.

[11] V.Z. Bermudez, L.D. Carlos, L. Alcácer, Chem. Mater 11 (1999) 569-580.

[12] P.A. Obara, V.H.V. Sarmento, S.J.L. Ribeiro, M. Nalin, C. Molina, Opt. Mater. 46 (2015) 64-69.

[13] M. Choi, Y. Kim, C. Ha, Prog. Polym. Sci. 33 (2008) 581-630.

[14] F. Tricot, F. Vocanson, D. Chaussy, D. Beneventi, S. Reynaud, Y. Lefkir, N. Destouches, RSC Adv. 4 (2014) 61305-61312.

[15] G. Filpo, F.P. Nicoletta, G. Chidichimo, Chem. Mater 18 (2006) 4662-4666.

[16] A. Bessière, J.C. Badot, M.C. Certiat, J. Livage, V. Lucas, N. Baffier, Electrochimica Acta 46 (2001) 2251-2256.

[17] P.T. Anastas, M.M. Kirchhoff, Acc. Chem. Res. 35 (2002) 686-694.

[18] Y. Zare, Waste Manag. 33 (2013) 598-604.

[19] G. Curtzwiler, K. Vorst, J.E. Danes, R. Auras, J. Singh, J. Plastic Film Sheeting 27 $(1-2)(2011) 65-86$

[20] O. Mrad, S. Saloum, A. Mariri, Vacuum 88 (2013) 11-16.

[21] J.M. Andanson, S.G. Kazarian, Macromol. Symp. 265 (2008) 195-204.

[22] Z. Li, Y. Liu, H. Liu, P. He, Q. Zhang, J. Li, Solid State Ionics 177 (2006) $1281-1286$.

[23] J.F. Keggin, Proceedings of the Royal Society of London, Series A Containing Papers Mat. Physical Char. 144 (no 851) (1934) 75-100.

[24] L.D. Carlos, V. de Zéa Bermudez, R.A. Sá Ferreira, L. Marques, M. Assunção, Chem. Mater 11 (1999) 581-588.

[25] G.M. Varga, E. Papaconstantinou, M.T. Pope, Inorg. Chem. 9 (no 3) (1970) $662-667$.

[26] M.T. Pope, Heteropoly and Isopolyoxometalates, Springer-Verlag, Berlim, 1983.

[27] X. Zhong, Y. Liu, X. Tang, Q. Wu, L. Li, Y. Yu, Colloid. Polym. Sci. 290 (2012) 1683-1693. 